\title{
Shopping Attributes Berdasarkan Motivasi dan Loyalitas Wisatawan Nusantara Kota Bandung
}

\author{
Nunik Fadjrina ${ }^{1}$, Vitha Octavanny ${ }^{2}$, Wilson Matara ${ }^{3}$ \\ ${ }^{1}$ Sekolah Tinggi Pariwisata Bandung, fadjrinaputri@gmail.com \\ ${ }^{2}$ Sekolah Tinggi Pariwisata Bandung, vithaoctavanny@gmail.com \\ ${ }^{3}$ Sekolah Tinggi Pariwisata Bandung, wilsonmatara21@gmail
}

\begin{abstract}
ABSTRAK
Wisata belanja adalah salah satu sumber pendapatan pada sebuah destinasi wisata. Untuk mengoptimalkan pendapatan tersebut, sebuah destinasi perlu memperhatikan shopping attributes yang ditawarkan agar wisatawan mau berbelanja kembali dan bersedia untuk mengatakan hal-hal positif mengenai wisata belanja di Kota Bandung kepada orang lain. Maka, tujuan penelitian ini adalah untuk mengetahui gambaran shopping attributes berdasarkan motivasi dan loyalitas wisatawan nusantara yang berkunjung ke Kota Bandung. Berdasarkan hasil penelitian yang dilakukan pada 12 partisipan dengan menggunakan metode kualitatif, diketahui bahwa pelayanan karyawan, kenyamanan dan value dari produk yang ditawarkan pada dua kawasan wisata belanja di Kota Bandung memiliki persepsi paling baik diantara komponen shopping attributes lainnya. Wisatawan yang berbelanja ke Kota Bandung sebagian besar dilatarbelakangi oleh motif hedonik dan perilaku wisatawan mencerminkan karakteristik loyalitas.
\end{abstract}

Kata kunci : wisata belanja, atribut wisata belanja, destinasi wisata, loyalitas wisatawan

\section{ABSTRACT}

Shopping tourism is one of revenue sources at the tourist destination. To optimize the revenue, a destination needs to pay attention to the shopping attributes offered so that tourists want to shop back and are willing to say positive things about shopping in Bandung to others. Thus, the purpose of this study is to determine the picture of shopping attributes based on the motivation and loyalty of tourists visiting the city of Bandung. Based on the results of research conducted on 12 participants using qualitative methods, it is known that employee service, convenience and value of products offered in two shopping areas in Bandung City has the best perception among other shopping attributes components. Tourists who shop to the city of Bandung mostly are motivated by hedonic motivation and tourist behavior reflects the characteristics of loyalty.

Keywords: shopping tourism, shopping attributes, tourism destination, tourist loyalty

Naskah diterima : 10 Juli 2017, Naskah dipublikasikan : 15 September 2018

ISSN: 2355-6587, e-ISSN: 2528-2220

http://ejournal.bsi.ac.id/ejurnal/index.php/jp 


\section{PENDAHULUAN}

Kegiatan belanja telah melekat pada perilaku wisatawan dan merupakan komponen yang mengalami pertumbuhan dari rantai nilai pariwisata (UNWTO, 2014). Hubungan antara belanja dan pariwisata dapat dipahami dalam dua istilah - Tourist Shopping dan Shopping Tourism. Pada istilah pertama, kegiatan belanja adalah bagian dari itinerary wisatawan. Sedangkan istilah kedua, belanja adalah motif utama untuk berwisata (Tosun, Temizkan, Timothy, \& Fyall, 2007). Dalam konteks shopping tourism atau wisata belanja, aktifitas belanja dan fasilitas nya merupakan daya tarik wisata. Lebih lanjut, wisata belanja memberikan kontribusi untuk penciptaan lapangan kerja dan membangun citra yang baik ditengah tingginya kompetisi yang ada. (Chang, Yang, \& Yu, 2006; Tosun et al., 2007; Turner \& Reisinger, 2000; Yüksel \& Yüksel, 2007).

Kebutuhan untuk melakukan penelitian terhadap tourist shopping pada dasarnya muncul dari sejumlah penelitian yang menemukan bahwa perilaku wisatawan berbeda ketika mereka berbelanja disaat traveling dibandingkan dengan yang mereka lakukan di tempat tinggalnya (Oh, Cheng, Lehto, \& O'Leary, 2004; Wong \& Wan, 2013). Fenomena tersebut membuat pelaku usaha wisata belanja perlu mempertimbangkan jenis atribut yang penting untuk wisatawan, dan bagaimana persepsi nilai dibentuk ketika mereka berbelanja disaat travelling. (Lloyd, Yip, \& Luk, 2011). Terkadang, keinginan untuk berbelanja dapat menjadi motivasi utama untuk berwisata (Timothy \& Butler, 1995). Semenjak tahun 2000, akademisi telah menunjukkan ketertarikan besar dalam mengkaji alasan orang termotivasi untuk berbelanja disaat berwisata, dan bagaimana mereka dipengaruhi oleh lingkungan dan fasilitas destinasi wisata belanja.Penelitian sebelumnya telah mengeksplorasi beragam topik mengenai wisata belanja, diantaranya adalah shopping value (Albayrak, Caber, \& Çömen, 2016) shopping experiences (Kozak, 2016) dan shopping behavior (Kuo, hu, \& Yang, 2013). Meskipun kajian terkait wisata belanja cukup banyak ditemui, studi komprehensif mengenai peran shopping attribute dalam menciptakan loyalitas wisatawan masih sangat sedikit.

Pentingnya wisata belanja telah menjadikan banyak destinasi wisata saat ini secara serius mengembangkan kota atau daerahnya sebagai destinasi wisata belanja. Kota yang dikenal sebagai wisata belanja di Indonesia adalah Kota Bandung. Wisatawan yang datang ke Bandung selain menikmati wisata alam, wisata edukasi, wisata sejarah, dan wisata kuliner, juga menyempatkan untuk berbelanja. Wisata belanja di Kota Bandung terus berkembang dengan meningkatnya jumlah distro, factory outlet (FO), mall, trade center, butik yang tersebar dimana-mana. Upaya yang dilakukan pemerintah Kota Bandung dalam pengembangan wisata belanja yaitu dengan membagi kawasan agar memudahkan wisatawan berbelanja secara terpusat (RIPPDA Kota Bandung tahun 2012-2025) diantaranya kawasan wisata belanja Setiabudhi, R.E Martadinata, Cihampelas yang terkenal dengan pusat Factory Outlet, kawasan Cihampelas juga merupakan sentra jeans, kawasan Cibaduyut untuk sentra industri sepatu. Namun demikian, meningkatnya jumlah wisatawan yang melakukan belanja tidak diiringi dengan pertumbuhan tingkat loyalitas wisatawan yang pada saat ini masih rendah (Park, Reisinger, \& Kang, 2008).

Beberapa wisatawan belanja, terutama konsumen muda tidak dapat bertahan pada suatu tempat belanja tertentu, mereka cenderung mengunjungi beberapa toko sebelum mengambil keputusan pembelian dan untuk melakukan pembelian ulang karena wisatawan tidak memiliki daftar khusus untuk berbelanja, bahkan berbelanja sering terjadi sebagai perjalanan yang tidak terencana dan hal itulah yang membuat wisatawan tidak dapat setia ketika berbelanja (Nguyen, Nguyen, \& Barrett, 2007). Dengan demikian, penting untuk meningkatkan pemahaman terkait alasan wisatawan menjadi loyal terhadap suatu destinasi wisata belanja.

Lebih lanjut, berdasarkan hasil penelitian diketahui bahwa terdapat beberapa faktor yang mempengaruhi loyalitas wisatawan belanja diantaranya motivasi wisatawan serta daya tarik suatu tempat belanja. (Irsan, 2011). Loyalitas pelanggan dapat terbentuk karena daya tarik shopping attribute suatu wisata 
belanja serta motivasi karena wisatawan memiliki keinginan untuk mencoba tempat belanja lain yang lebih baik, mencari suasana lingkungan yang baru dan lebih nyaman serta tertarik dengan produk/jasa yang ditawarkan oleh pesaing. (Kim \& Jin, 2001; Michon \& Chebat, 2004)

Berdasarkan permasalahan yang ada, penelitian ini hanya membatasi pada dua tempat perbelanjaan di Kota Bandung yaitu Factory Outlet di Jalan Setiabudhi dan Factory Outlet Heritage di Jalan R.E Martadinata mengingat waktu yang terbatas dan metode penelitian yang digunakan. Kajian ini disusun untuk menjawab pertanyaanpertanyaan berikut:

a) Bagaimana persepsi wisatawan terhadap shopping attributes di Kota Bandung?

b) Bagaimana motivasi wisatawan nusantara berbelanja ke Kota Bandung?

c) Bagaimana loyalitas wisatawan nusantara untuk belanja di Kota Bandung?

Adapun tujuan kajian ini adalah untuk mengetahui gambaran shopping attributes berdasarkan motivasi dan loyalitas wisatawan nusantara yang berkunjung ke kota Bandung. Sedangkan manfaat penelitian secara teoritis adalah untuk memperluas pemahaman terkait shopping attributes berdasarkan motivasi dan loyalitas wisatawan terhadap suatu destinasi wisata belanja. Dari perspektif praktis adalah penelitian ini diharapkan akan membantu manajer ritel dan stakeholders wisata belanja lainnya seperti operator pariwisata, organisasi pariwisata lokal, dan pemerintah agar dapat menciptakan strategi berkelanjutan untuk pengembangan destinasi wisata belanja yang dimiliki.

\section{KAJIAN LITERATUR \\ Shopping Attributes}

Berbagai istilah mengenai shopping attributes telah banyak diteliti sebelumnya, seperti online shopping attributes dan mall shopping attribute. Pada penelitian ini, istilah yang digunakan adalah shopping attributes yang berfokus pada wisata belanja fashion. Dalam fenomena sosial, berbelanja melibatkan lebih dari sekedar membeli produk (Tosun et al., 2007). Faktanya, hal tersebut mengandung faktor intangible dan tangible. Oleh karena itu, sebagai tambahan pada faktor tangible, seperti lokasi, jam kerja, kebersihan, tingkat harga, dan lain sebagainya, penelitian empiris lainnya mengenai perilaku wisatawan yang berbelanja sebaiknya mempertimbangkan faktor intangible, yang terdiri dari kontak interpersonal, atmosfir di dalam toko dan atmosfir diluar toko, termasuk juga masyarakat sekitar, aksesibilitas, dan kebersihan (Albayrak dkk., 2016).

Secara khusus, lingkungan di dalam dan di luar tempat perbelanjaan dan komunikasi dengan masyarakat sekitar menjadi lebih penting untuk wisatawan dibandingkan dengan kondisi tempat tinggal mereka. Faktor-faktor belanja tersebut dikenal sebagai "shopping attributes". Shopping attributes terdiri dari beragam faktor yang penting sebelum berbelanja, pada saat berbelanja, dan fase setelah berbelanja, seperti aksesibilitas toko/area, kebersihan, kualitas pelayanan, harga, dan sebagainya. Sebagai contoh, sebelum kegiatan belanja dilakukan, memberikan informasi harga yang aktual pada konsumen yang sering berbelanja akan menurunkan niat mereka untuk membeli dan mengantisipasi kepuasan, sedangkan konsumen dengan tujuan berbelanja dalam waktu dekat diharapkan untuk mentolerir harga tinggi (Haans, 2011). Beberapa studi menemukan bahwa pemilihan tempat perbelanjaan bergantung pada kenyamanan dan economic attributes, seperti aksesibilitas, tampilan layanan (bank, restoran) dan recreational attributes (fashionability, keragaman produk) (Dawson, Bloch, \& Ridgway, 1990).

Sebagai hasil dari pengalaman berbelanja, yang dibentuk oleh beragam jenis shopping attributes pada suatu destinasi, wisatawan diharapkan memperoleh persepsi nilai positif. Shopping attributes yang baik dianggap dapat menjadi salah satu strategi pemasaran yang dapat memberikan stimuli ketika konsumen berbelanja sehingga dapat tercipta rasa puas dan loyalitas terhadap suatu destinasi wisata belanja.

\section{Dimensi Shopping Attributes}


Pada awal tahun 1990, banyak studi berusaha untuk mengidentifikasi shopping attributes yang paling penting di suatu destinasi. Pada salah satu studi bertujuan untuk mengidentifkasi shopping attributes yang utama dan pengukuran dari pengaruhnya terhadap persepsi nilai wisatawan. Berdasarkan tinjauan literatur (Brown, Mowen, Donavan, \& Licata, 2002; Michon \& Chebat, 2004). model penelitian mengenai shopping attributes terdiri dari quality of customer services, convenience, environment, quality of retailers, dan rewards. Convenience adalah salah satu bagian dari shopping attributes yang banyak diinginkan orang (Richbell \& Kite, 2007).

Keown (1989) mengidentifikasi 16 attributes di Hong Kong dan dibandingkan dengan pengalaman belanja dari wisatawan Jepang dengan warga negara lain. Humanside attributes (kerapihan, kejujuran dan keramah-tamahan dari tenaga penjual) lebih penting untuk wisatawan Jepang, dan juga menjadi alasan utama untuk ketidakpuasan, studi menemukan bahwa wisatawan lain merasakan pengalaman belanja yang lebih baik. Pada studi lainnya, yang dilakukan di Hong Kong, Heung \& Cheng (2000) mengidentifikasi 15 shopping attributes, yang digolongkan berdasarkan empat faktor: "tangibles quality" (physical setting, jam buka, dan kebersihan), "staff service quality" (bahasa, kemampuan, sikap), "product value" (harga, value for money), dan "product reliability". Penelitian terhadap sebuah kelompok wisatawan China ke Taiwan, mengidentifikasi 20 attributes yang diklasifikasikan dibawah lima dimensi: "physical attraction", "staff service quality", "product features", "uniqueness and convenience", dan "discount and display". Hasil dari studi tersebut menunjukkan bahwa wisatawan hanya merasa puas dengan layanan “home delivery service".(Lin \& Lin, 2006) Lebih lanjut, studi mengenai wisatawan domestik yang berkunjung ke daerah Gold Coast dan Queensland oleh Turner \& Reisinger (2000) mengindikasikan bahwa, "cost", "shop presentation", dan "product display" attributes memiliki pengaruh terbesar pada kepuasan wisatawan dengan pengalaman belanja mereka. Pada studi terbaru, Tosun,. dkk (2007) menginvestigasi perspesi wisatawan terhadap shopping attributes di daerah Cappadocia Turki dan memperoleh dua dimensi: "tangible quality of shops" dan "staff service quality". Dalam penelitian ini shopping attributes diukur berdasarkan lima faktor, yaitu, value, service, convenience, attractiveness, dan accesibility (Fowler, Hurst, Niehm, Strohbehn, \& Meyer, 2012; Lehew \& Wesley, 2007; Lin \& Lin, 2006; Yeung, Wong, \& Ko, 2004). Alasan peneliti menggunakan lima dimensi karena dimensi tersebut dianggap sesuai dengan kondisi objek pada penelitian ini serta mampu mengukur tingkat kualitas shopping attributes.

\section{Motivasi Berbelanja}

Menurut Stephen P. Robbins (2001) motivasi adalah kesediaan untuk mengeluarkan tingkat upaya yang tinggi untuk tujuan organisasi yang dikondisikan oleh kemampuan upaya itu untuk memenuhi beberapa kebutuhan individual, sedangkan berbelanja merupakan suatu kegiatan membeli suatu produk untuk memenuhi kenginan. Motivasi berbelanja terbagi menjadi dua yaitu motif belanja utilitarian dan belanja hedonik.

Motif belanja hedonik adalah perilaku yang mengacu pada kecenderungan untuk rekreasi, kesenangan, intrinsik, dan orientasi pada rangsangan suatu motivasi, karena berbelanja merupakan suatu hal yang menarik dan dapat menghilangkan rasa jenuh. Selain itu konsumen yang memiliki sifat hedonik ini seringkali tida peduli berapa banya uang yang dikeluarkan untuk berbelanja demi mendapatkan kepuasan dan kebahagiaan (Arnold \& Reynolds, 2003).

Babin dkk (1994) menjelaskan motif utilitarian merupakan motif seseorang yang berorientasi pada kualitas dari suatu produk dan rasional ketika berbelanja memikirkan dari suatu manfaat dan kebutuhannya. Tipe konsumen ini akan lebih konsisten kepada tujuan utamanya tidak terpengaruh terhadap jenis barang lain atau seperti adanya potongan harga atau tidak.

\section{Loyalitas Wisatawan}

Christopher \& Wirtz (2018) menyatakan bahwa loyalitas adalah suatu kesediaan wisatawan untuk melanjutkan ativitas terhadap suatu produk wisata dalam jangka waktu yang panjang dan melakukan aktivitas secara berulang. 
Dalam wisata belanja, loyalitas wisatawan menjadi penting karena pengunjung yang telah berulang kali berbelanja akan lebih menghabiskan pengeluaran ketika belanja dibandingkan dengan pengunjung yang baru pertama kali berbelanja (Cheng-Lu Wang, Zhen-Xiong Chen, Allan K.K. Chan, 2000). Salah satu prediktor loyalitas adalah shopping attributes yang dapat memberikan stimulus kepada pembelanja (Yanuar, 2013, Subagio, 2011). Studi menemukan bahwa memperoleh kepuasan dari shopping attributes memainkan peran yang signifikan dalam mengembangkan loyalitas wisatawan terhadap destinasi wisata belanja (Suhartanto, Ruhadi, \& Triyuni, 2016).

Loyalitas wisatawan dapat diukur melalui dua dimensi, yaitu supportive behaviors yang terdiri dari positive word-of-mouth, mendorong orang lain untuk mengunjungi suatu destinasi, dan membagikan foto suatu destinasi. Dimensi kedua adalah future visit intention yan terdiri dari kemungkinan untuk berkunjung kembali, kesediaan untuk tetap berkunjung kembali meskipun terdapat kenaikan harga dan menjadikan suatu destinasi sebagai pilihan utama untuk berlibur (Leong, Yeh, Hsiao, \& Huan, 2015). Berdasarkan teori loyalitas yang ada, maka pengukuran loyalitas dalam penelitian ini menggunakan dimensi supportive behaviors dan future visit intention karena dianggap paling sesuai dengan kondisi saat ini dan tema penelitian yang diambil.

\section{METODE PENELITIAN}

Metode yang digunakan dalam penelitian ini adalah metode deskriptif dengan pendekatan kualitatif. Penggunaan metode kualitatif ditujukan untuk menjelaskan secara mendalam tentang bagaimana persepsi wisatawan terhadap shopping attributes dan dimensi nya, motivasi wisatawan juga loyalitas wisatawan nusantara yang berkunjung ke Kota Bandung.. Sampel dalam penelitian kualitatif disebut juga sampel teoritis karena tujuan penelitian kualitatif adalah untuk menghasilkan teori (Sugiyono, 2014). Untuk menentukan partisipan, peneliti menggunakan non probability sampling dengan teknik purposive sampling, yaitu dipilih dengan pertimbangan dan tujuan tertentu (Sugiyono, 2014). Pertimbangan tertentu ini adalah partisipan yang dianggap paling mengetahui tentang apa yang peneliti harapkan sehingga akan memudahkan untuk menjelajahi situasi yang diteliti. Dengan demikian, partisipan yang dipilih adalah 12 (dua belas) wisatawan nusantara yang telah berkunjung ke pusat perbelanjaan di Kota Bandung lebih dari dua kali. Sedangkan lokasi penelitian akan dilakukan di dua tempat belanja Kota Bandung yaitu Factory Outlet Rumah Mode di Jalan Setiabudhi dan Factory Outlet Heritage di Jalan R.E Martadinata.

Penelitian mengenai shopping attributes relatif masih sedikit, dan belum banyak orang mengetahui bagian-bagian dari shopping attributes. Oleh karena itu, observasi dan wawancara semi terstruktur dinilai sesuai untuk memperoleh persepsi wisatawan terhadap shopping attributes, motivasi wisatawan dan juga loyalitas wisatawan nusantara Kota Bandung. Wawancara semi terstruktur ini dilakukan dengan menggunakan pedoman wawancara sebagai batasan pertanyaan antara penulis dengan wisatawan yang menjadi sampel dalam penelitian ini.

\section{PEMBAHASAN}

\section{Profil Partisipan}

Seperti yang telah diuraikan sebelumnya, 12 wisatawan nusantara bersedia menjadi partisipan dalam penelitian ini. Partisipan tersebut terdiri dari 9 perempuan dan 3 lakilaki. Sebanyak enam partisipan berusia dibawah 30 tahun. Enam Partisipan lainnya berusia 31 sampai dengan 52 tahun. Berdasarkan observasi selama penulis mengunjungi objek penelitian, diketahui bahwa banyak wisatawan yang berkunjung masih dalam usia produktif. Pekerjaan partisipan sangat beragam dan dapat dilihat secara rinci pada Tabel 1 Umumnya wisatawan telah berkunjung ke Kota Bandung lebih dari lima kali (84\% dari total partisipan), sementara partisipan lainnya pernah berkunjung ke Bandung sebanyak tiga sampai empat kali. Frekuensi partisipan berkunjung ke Bandung lebih dari lima kali disebabkan oleh asal tinggal partisipan yang jaraknya cukup dekat dengan Bandung. Rata-rata lama berkunjung partisipan di Bandung, umumnya partisipan tinggal di Bandung selama dua sampai dengan tiga hari $(91.7 \%$ dari total 
partisipan). Hanya satu partisipan yang menetap di Bandung sekitar satu sampai dua hari saja. Waktu terlama partisipan untuk tinggal di Bandung hanya sampai tiga hari.

Tabel 1

Profil Pekerjaan

\begin{tabular}{llllll}
\hline No & $\begin{array}{l}\text { Jenis } \\
\text { Kelamin }\end{array}$ & Pekerjaan & Asal Tinggal & $\begin{array}{l}\text { Frekuensi } \\
\text { ke } \\
\text { Bandung }\end{array}$ & $\begin{array}{l}\text { Rata-Rata } \\
\text { Lama } \\
\text { Tinggal }\end{array}$ \\
\hline 1 & Perempuan & Bidan & Ciamis & $>5$ kali & 3 hari \\
\hline 2 & Perempuan & Swasta & Demak & $>5$ kali & $2-3$ hari \\
\hline 3 & Perempuan & $\begin{array}{l}\text { Pegawai } \\
\text { Bank }\end{array}$ & Cianjur & $>5$ kali & 2 hari \\
\hline 4 & Perempuan & Notaris & Jakarta & $>5$ kali & $1-2$ hari \\
\hline 5 & Laki-Laki & Wirausaha & Jakarta & 4 kali & $2-3$ hari \\
\hline 6 & Perempuan & PNS & $\begin{array}{l}\text { Banjar } \\
\text { masin }\end{array}$ & $>5$ kali & $2-3$ hari \\
\hline 7 & Perempuan & Swasta & Jakarta & 3 kali & 2 hari \\
\hline 8 & Perempuan & BUMN & Yogyakarta & $>5$ kali & $2-3$ hari \\
\hline 9 & Perempuan & Swasta & Jakarta & 4 kali & 2 hari \\
\hline 10 & Perempuan & Perawat & Tangerang & 3 kali & $2-3$ hari \\
\hline 11 & Laki-Laki & Wirausaha & Jakarta & $>5$ kali & $2-3$ hari \\
\hline 12 & Laki-Laki & Hotelier & Indramayu & $>5$ kali & $2-3$ hari \\
\hline
\end{tabular}

Sumber: Hasil Pengolahan Data (2018)

Persepsi Wisatawan Terhadap Shopping Attributes di Kota Bandung

Partisipan diberikan pertanyaan terkait persepsi terhadap shopping attributes di Kota Bandung mengenai value, service, convenience, attractiveness, dan accessibility. Berdasarkan hasil penelitian dapat diketahui bahwa seluruh partisipan menyatakan bahwa produk yang ditawarkan di tempat perbelanjaan Kota Bandung memiliki kualitas yang baik tetapi tidak jarang ada barang yang out of date dan tidak mengikuti tren. Begitu juga dengan pelayanan dan pengetahuan karyawan mengenai produk yang ditawarkan, seluruh partisipan menyatakan bahwa pelayanan dan juga pengetahuan karyawan dinilai baik, karyawan dapat menjawab ketika partisipan menanyakan ukuran, model dan alternatif pilihan lainnya. Jawaban dari seluruh partisipan dapat dilihat pada Tabel 2. Dalam segi harga, sebagian partisipan mengatakan bahwa harga yang ditawarkan pada tempat perbelanjaan mempengaruhi mereka untuk berbelanja di Kota Bandung. Empat diantaranya bahkan menyatakan bahwa dengan adanya diskon yang ditawarkan juga mempengaruhi partisipan tersebut untuk berbelanja di Bandung. Mereka berharap lebih banyak diskon yang ditawarkan di Factory Outlet Rumah Mode dan Heritage. Sebagian partisipan lainnya mengatakan bahwa harga dan diskon yang ditawarkan tempat perbelanjaan di Bandung tidak mempengaruhi mereka untuk berbelanja di Bandung dikarenakan harga yang dirasa standar, bahkan ada barang tertentu yang dirasa mahal serta diskon yang seringkali tidak sesuai dengan waktu partisipan berkunjung ke Bandung. Hasil penelitian ini berbeda dengan hasil penelitian dari Kim \& Jin (2001) menyatakan bahwa harga dan kualitas merupakan salah satu yang paling penting dimensi yang penting dari shopping attributes.

Seluruh partisipan menilai bahwa tempat perbelanjaan di Bandung memiliki keamanan yang baik, hal ini dapat dilihat dari adanya staf security yang memadai dan fasilitas CCTV. Namun demikian, satu partisipan memiliki persepsi yang kurang baik terhadap keamanan tempat belanja di Bandung karena pernah kehilangan sebuah handphone pada saat kondisi tempat perbelanjaan sedang ramai. Dalam segi kenyamanan, seluruh partisipan merasa bahwa tempat perbelanjaan di Bandung memberikan rasa nyaman saat berbelanja, hal ini timbul karena atmosfir 
yang sejuk, adanya fasilitas penyediaan makanan dan minuman khas Bandung, pelayanan karyawan yang baik, dan kebersihan tempat berbelanja (Seluruh partisipan menilai kebersihan tempat belanja di Bandung sudah terjaga dengan baik). Untuk partisipan yang membawa anak merasa terbantu dengan adanya tempat bermain anak pada salah satu tempat perbelanjaan di Bandung.

Penelitian ini memperoleh persepsi partisipan terhadap tampilan produk, brand (merek), keragaman produk dan keunikan produk yang ditawarkan di tempat perbelanjaan Kota Bandung. Secara keseluruhan, partisipan menilai bahwa tampilan produk yang di tempat perbelanjaan menarik untuk dilihat, merek yang ditawarkan beragam dan cukup lengkap, namun terdapat partisipan yang menyatakan bahwa mereka tidak melihat merek ketika berbelanja, dasar keputusan pembelian dipengaruhi oleh tampilan yang bagus dan nyaman dipakai. Produk yang ada pada tempat perbelanjaan Kota Bandung dinilai beragam, mulai dari pakaian, tas, sepatu, dompet, ikat pinggang, aksesoris, scarf dan lain sebagainya.

Lebih lanjut, partisipan mengemukakan bahwa terdapat produk tertentu yang memiliki keunikan, antara lain syal, sepatu, dan produk hand-made. Dua partisipan menyatakan bahwa sebetulnya yang unik itu merupakan arsitektur dan suasana tempat belanja itu sendiri, bukan produknya. Dua partisipan lainnya menyatakan bahwa produk yang ada pada tempat perbelanjaan Kota Bandung tidak memiliki keunikan, karena sama saja dengan yang ada di kota-kota besar lainnya, juga terkadang barang-barangnya merupakan koleksi lama yang tidak diperbaharui.

Pada saat partisipan diberikan pertanyaan terkait kondisi lalu lintas menuju tempat perbelanjaan di Bandung yang dikunjungi, mereka mengakui bahwa kondisi lalu lintas terutama saat weekend dan hari libur sangat padat atau macet. Tetapi hal ini bukan menjadi suatu masalah bagi partisipan, bahkan mereka mencoba menikmati kemacetan yang terjadi. beberapa diantaranya dapat menyusun strategi yaitu dengan menginap di hotel yang dekat dengan tempat perbelanjaan, menggunakan kereta api, dan mengambil cuti di hari biasa. cara tersebut dilakukan untuk menghindari kemacetan di dalam kota Bandung.

Hasil penelitian ini mendukung penelitian dari Suhartanto, dkk (2016) dan Huang \& Hsieh (2011) yang menemukan bahwa indikator service (pelayanan dan pengetahuan karyawan) memiliki persepsi paling baik dalam pandangan wisatawan, disusul oleh indikator convenience dimana seluruh partisipan merasa nyaman saat berbelanja di Bandung dan indikator value dimana wisatawan memiliki persepsi yang positif pada kualitas produk di Factory Outlet Rumah Mode dan Heritage Bandung. Sesuai dengan hasil penelitian Suhartanto, dkk (2016) bahwa wisatawan memiliki persepsi negatif terhadap kondisi lalu lintas menuju tempat perbelanjaan di Kota Bandung. Begitupun dengan hasil penelitian ini yang menemukan bahwa seluruh partisipan merasa Bandung sudah semakin padat dan macet di saat weekend dan hari libur.

Pada kebanyakan Kota besar di Indonesia, termasuk Bandung, lalu lintas kendaraannya buruk, walaupun hal tersebut adalah faktor penting untuk menarik kunjungan wisatawan (Hurst dan Nieh, 2012). Namun demikian, rata-rata partisipan tidak merasa bahwa kemacetan di Kota Bandung merupakan masalah yang besar, mereka cenderung menikmati atau mengatur strategi seperti menginap di hotel yang berada di pusat kota atau bagi partisipan yang tidak mau menemui kemacetan, maka berkunjung ke Bandung pada hari biasa.

\section{Motivasi Wisatawan Nusantara Berbelanja ke Kota Bandung}

Pada saat partisipan diberikan pertanyaan mengenai motivasi berbelanja ke Kota Bandung, jawaban yang diperoleh cukup beragam, yaitu mulai dari mengisi waktu luang disaat liburan, mencari kesenangan karena dengan belanja ke Bandung dapat menghilangkan stress, jenuh dan berkunjung ke kerabat yang ada di Bandung sehingga dapat sedikit meluangkan waktu untuk berbelanja. Sebagian partisipan memiliki motivasi belanja ke Bandung dilatarbelakangi oleh tujuan untuk memperhatikan kebutuhan dan manfaat dari produk yang akan dibeli. Sembilan partisipan lainnya mengemukakan bahwa motivasi mereka untuk berbelanja ke Kota Bandung didasari dengan adanya 
kebutuhan untuk menghilangkan stress dan jenuh, atau dengan kata lain kegiatan belanja merupakan suatu kesenangan tersendiri.

Berdasarkan hasil penelitian dapat diketahui bahwa partisipan senang mengunjungi Bandung karena dekat dengan tempat wisata yang membuat dirinya bisa berlibur bersama keluarga yang dibawanya disamping hanya untuk berbelanja. Berlibur di Bandung merupakan tujuan lain selain mereka berbelanja, bercengkrama dengan kerabat yang ada di Bandung merupakan hal yang ingin didapatkan dari sebagian partisipan, banyak alasan mereka mengunjungi kerabat yang ada di Bandung yaitu karena pernah berkuliah di Bandung atau karena pernah tinggal di Bandung untuk waktu yang cukup lama. Sehingga secara keseluruhan, partisipan berkunjung ke Kota Bandung dengan alasan memenuhi kebutuhan diri untuk mendapatkan kesenangan, mencari hiburan dan menghilangkan stress serta kejenuhan. Hasil penelitian ini sesuai dengan penelitian Nguyen (2007) yang menyatakan bahwa hedonic shopping motivation mengacu pada rekreasi, hiburan, kesenangan. Sedangkan utilitarian shopping motivation mengacu pada kegunaan dan orientasi pada produk serta lebih rasional (Babin dkk, 1994).

Banyaknya partisipan yang berbelanja kembali ke Bandung karena motif hedonik sesuai dengan hasil penelitian yang menyimpulkan bahwa aspek hedonik dalam berbelanja memiliki peran signifikan dalam membentuk customer loyalty (Alexandris, Kouthouris, \& Meligdis, 2006; Kuo et al., 2013; Kyle, Graefe, Manning, \& Bacon, 2004; Thaichon, Lobo, \& Quach, 2016). Hasil penelitian ini juga mendukung Yuksel dan Yuksel (2007) yang menyatakan bahwa aspek hedonik dalam belanja menjadi faktor yang signifikan untuk melakukan pembelian.

\section{Loyalitas Wisatawan Nusantara Kota Bandung}

Hasil penelitian menunjukkan bahwa Positive word of mouth mendapatkan tanggapan yang positif dari seluruh partisipan, mereka bersedia merekomendasikan orang lain terutama orang-orang terdekat untuk berbelanja ke Kota Bandung, bahkan beberapa partisipan mengaku bahwa mereka belanja ke Bandung atas dasar dorongan dari teman. Kecenderungan untuk merekomendasikan suatu destinasi kepada orang lain dianggap sebagai indikator yang jelas dari loyalitas (Cossío-Silva, Revilla-Camacho, \& VegaVázquez, 2018). Niat untuk merekomendasikan suatu destinasi ini merupakan salah satu faktor penentu kesuksesan karena resiko yang dapat dirasakan dalam memilih destinasi wisata membutuhkan informasi yang valid dan terpercaya. Dalam hal ini, referensi yang diterima dari orang lain akan mempengaruhi pilihan destinasi (Kivela \& Crotts, 2006).

Sebagian besar dari partisipan tidak terlalu menyukai eksistensi diri berupa membagikan foto perjalanannya ke Kota Bandung kepada orang banyak, hal ini dikarenakan sudah seringnya partisipan tersebut berkunjung ke Bandung, sehingga partisipan menjadi kurang antusias dalam hal membagikan momen berkunjung ke Bandung di media sosial. Selain positive word of mouth, pertanyaan mengenai niat partisipan untuk berkunjung kembali pun mendapatkan tanggapan yang sangat positif, dibuktikan dengan seluruh partisipan yang menyatakan bahwa mereka sangat ingin untuk kembali berkunjung dan berbelanja di Bandung. Niat untuk berkunjung kembali ke suatu destinasi merupakan komponen kunci dari loyalitas dan telah banyak peneliti yang membahas mengenai konsep ini, mencoba untuk menentukan faktor-faktor yang dapat memperoleh keuntungan dari adanya kunjungan berulang (Backman \& Crompton, 1991).

Dalam loyalitas ada pula supportive behavior yang terdiri dari membagikan foto saat berkunjung, kesediaan berkunjung apabila ada kenaikan harga dan menjadikan Bandung sebagai destinasi utama untuk belanja (Leong dkk., 2015). Berdasarkan hasil penelitian, diketahui bahwa partisipan bersedia berkunjung kembali ke Bandung untuk berbelanja walaupun ada kenaikan harga. Secara keseluruhan, perilaku partisipan telah mencerminkan karakteristik loyalitas wisatawan yang dikeluarkan oleh peneliti terdahulu

\section{PENUTUP}

Dua istilah - store attributes dan shopping attributes sering muncul dalam penelitian mengenai wisata belanja. Dalam penelitian ini menggunakan istilah shopping attributes yang didefinisikan sebagai beragam faktor 
tangible dan intangible yang mempengaruhi kegiatan wisata belanja, baik itu sebelum belanja, pada saat belanja dan setelah belanja. Penelitian ini mengkaji berbagai literatur mengenai shopping tourism dan shopping attributes.

Berdasarkan hasil penelitian, dapat diketahui bahwa persepsi wisatawan terhadap shopping attributes di dua tempat perbelanjaan di Kota Bandung sudah cukup baik. Pelayanan karyawan, kenyamanan dan nilai dari produk yang ditawarkan memperoleh persepsi paling baik bagi wisatawan. Lebih lanjut, persepsi wisatawan terhadap aksesibilitas menuju kawasan wisata belanja Kota Bandung kurang begitu baik dikarenakan kondisi lalu lintas Kota Bandung yang sering macet pada saat akhir pekan dan hari libur. Sebagian partisipan mengemukakan bahwa salah satu penyebab kemacetan adalah kurangnya daya tampung fasilitas parkir pada kedua factory outlet yang diteliti.

Wisatawan yang berbelanja ke Kota Bandung sebagian besar didorong oleh motif hedonik yaitu perilaku yang mengacu pada kecenderungan untuk rekreasi, kesenangan, intrinsik, dan orientasi pada rangsangan suatu motivasi, karena berbelanja merupakan suatu hal yang menarik dan dapat menghilangkan rasa jenuh, stress. Selain itu konsumen yang memiliki sifat hedonik ini seringkali tidak peduli berapa banyak uang yang dikeluarkan untuk berbelanja demi mendapatkan kepuasan dan kebahagiaan. Oleh sebab itu orang yang berbelanja didasari oleh motif hedonik akan cenderung lebih loyal. Indikator loyalitas wisatawan yang mendapatkan tanggapan paling positif adalah niat untuk berkunjung kembali serta positive word of mouth. Sementara itu wisatawan yang berbelanja ke Kota Bandung kurang suka membagikan foto ketika berkunjung dan empat wisatawan menyatakan bahwa Bandung masih menjadi destinasi alternatif untuk wisata belanja.

Penelitian ini memiliki beberapa kelemahan, yaitu objek penelitian yang masih terbatas; hanya dua tempat perbelanjaan di Kota Bandung, sehingga dinilai masih kurang mewakili gambaran mengenai shopping attributes pada tempat wisata belanja di Kota Bandung. Selain itu, partisipan dalam penelitian ini jumlahnya masih sedikit mengingat keterbatasan waktu yang dimiliki oleh penulis, sehingga dinilai masih kurang mewakili gambaran mengenai motivasi dan loyalitas wisatawan nusantara Kota Bandung.

Penelitian selanjutnya disarankan untuk mengambil objek penelitian wisata belanja yang lebih luas, tidak hanya factory outlet, tetapi juga mall dan pusat perbelanjaan lain yang ada di Kota Bandung. Lebih lanjut, metode penelitian yang dapat digunakan pada penelitian berikutnya dapat menggunakan metode penelitian kuantitatif sehingga dapat diketahui dimensi shopping attributes apa yang paling mempengaruhi motivasi dan loyalitas wisatawan nusantara Kota Bandung.

\section{REFERENSI}

Albayrak, T., Caber, M., \& Çömen, N. (2016). Tourist shopping: The relationships among shopping attributes, shopping value, and behavioral intention. Tourism Management Perspectives, 18, 98-106. https://doi.org/10.1016/j.tmp.2016.01.00 7

Alexandris, K., Kouthouris, C., \& Meligdis, A. (2006). Increasing customers' loyalty in a skiing resort: The contribution of place attachment and service quality. International Journal of Contemporary Hospitality Management, 18(5), 414425.

https://doi.org/10.1108/09596110610673 547

Arnold, M. J., \& Reynolds, K. E. (2003). Hedonic shopping motivations. Journal of Retailing, 79(2), 77-95. https://doi.org/10.1016/S00224359(03)00007-1

Babin, B. J., Darden, W. R., \& Griffin, M. (1994). Utilitarian shopping value. Journal of Consumer Research, 20(4), 644-657. https://doi.org/DOI: http://dx.doi.org/10.1086/209376

Backman, S. J., \& Crompton, J. L. (1991). The usefulness of selected variables for predicting activity loyalty. Leisure Sciences, 13(3), 205-220. https://doi.org/10.1080/01490409109513 
138

Brown, T. J., Mowen, J. C., Donavan, D. T., \& Licata, J. W. (2002). The Customer Orientation of Service Workers: Personality Trait Effects on Self- and Supervisor Performance Ratings. Journal of Marketing Research, 39(1), 110-119.

https://doi.org/10.1509/jmkr.39.1.110.18 928

Chang, J., Yang, B. T., \& Yu, C. G. (2006). The moderating effect of salespersons' selling behaviour on shopping motivation and satisfaction: Taiwan tourists in China. Tourism Management, 27(5), 934-942. https://doi.org/10.1016/j.tourman.2005.0 6.001

Cheng-Lu Wang, Zhen-Xiong Chen, Allan K.K. Chan, Z.-C. Z. (2000). The influence of hedonic values on consumer behaviors: An empirical investigation in China. Journal of Global Marketing, 14(December 2015), 83-109. https://doi.org/10.1300/J042v14n01

Christopher, L., \& Wirtz, J. (2018). Essentials of Services Marketing, Global Edition, (January 2012), 705.

Cossío-Silva, F.-J., Revilla-Camacho, M.-Á., \& Vega-Vázquez, M. (2018). The tourist loyalty index: A new indicator for measuring tourist destination loyalty? Journal of Innovation \& Knowledge, 19.

https://doi.org/10.1016/j.jik.2017.10.003

Dawson, S., Bloch, P. H., \& Ridgway, N. M. (1990). Shopping Motives, Emotional States, and Retail Outcomes. Journal of Retailing, 66(4), 408. Retrieved from http://search.ebscohost.com/login.aspx?d irect $=$ true $\& d b=$ buh $\& A N=4667693 \&$ site $=$ ehost-live

Fowler, D. C., Hurst, J. L., Niehm, L. S., Strohbehn, C., \& Meyer, J. (2012). Tourism shopping in rural markets: A case study in rural Iowa. International
Journal of Culture, Tourism and Hospitality Research, 6(3), 194-208. https://doi.org/10.1108/17506181211246 357

Haans, H. (2011). Evaluating retail format extensions: The role of shopping goals. Journal of Retailing and Consumer Services, 18(5), 389-396. https://doi.org/10.1016/j.jretconser.2011. 05.001

Heung, V. C. S., \& Cheng, E. (2000). Assessing Tourists' Satisfaction with Shopping in the Hong Kong Special Administrative Region of China. Journal of Travel Research, 38(4), 396-404. https://doi.org/10.1177/00472875000380 0408

Huang, L.-Y., \& Hsieh, Y.-J. (2011). What Drives Consumer Impulse Buying? Evidence from a Retail Setting in Taiwan. Quality.

Irsan, Y. (2011). Pengaruh Atribut Supermarket Terhadap Motif Belanja Hedonik Motif Belanja Utilitarian Dan Loyalitas Konsumen. Jurnal Manajemen Pemasaran, 6(1), 8-21. Retrieved from http://puslit2.petra.ac.id/ejournal/index.p $\mathrm{hp} / \mathrm{mar} /$ article/view/18386

Keown, C. F. (1989). A Model Of Tourists' Propensity To Buy: The Case Of Japanese Visitors To Hawaii. Journal of Travel Research, 27(3), 31-34. https://doi.org/10.1177/00472875890270 0306

Kim, J. O., \& Jin, B. (2001). Korean consumers' patronage of discount stores: Domestic vs multinational discount store shoppers' profiles. Journal of Consumer Marketing, 18(3), 236-253. https://doi.org/10.1108/07363760110393 092

Kivela, J., \& Crotts, J. C. (2006). Tourism and Gastronomy: Gastronomy's Influence on How Tourists Experience a Destination. Journal of Hospitality and Tourism Research, 30(3), 354-377. 
https://doi.org/10.1177/10963480062867 97

Kozak, M. (2016). Bargaining Behavior and the Shopping Experiences of British Tourists on Vacation. Journal of Travel and Tourism Marketing, 33(3), 313-325. https://doi.org/10.1080/10548408.2015.1 051199

Kuo, Y. F., hu, T. L., \& Yang, S. C. (2013). Effects of inertia and satisfaction in female online shoppers on repeat $\square$ purchase intention:The moderating roles of word $\square$ of $\square$ mouth and alternative attraction. Managing Service Quality: An International Journal, 23(3), 168-187. https://doi.org/10.1108/09604521311312 219

Kyle, G., Graefe, A., Manning, R., \& Bacon, J. (2004). Predictors of behavioral loyalty among hikers along the Appalachian Trail. Leisure Sciences, 26(1), 99-118. https://doi.org/10.1080/01490400490272 675

Lehew, M. L. A., \& Wesley, S. C. (2007). Tourist shoppers' satisfaction with regional shopping mall experiences. International Journal of Culture, Tourism and Hospitality Research, 1(1), 82-96.

https://doi.org/10.1108/17506180710729 628

Leong, A. M. W., Yeh, S. S., Hsiao, Y. C., \& Huan, T. C. T. C. (2015). Nostalgia as travel motivation and its impact on tourists' loyalty. Journal of Business Research, 68(1), 81-86. https://doi.org/10.1016/j.jbusres.2014.05 .003

Lin, Y. H., \& Lin, K. Q. R. (2006). Assessing mainland Chinese visitors' satisfaction with shopping in Taiwan. Asia Pacific Journal of Tourism Research, 11(3), 247-268.

https://doi.org/10.1080/10941660600753 281
Lloyd, A. E., Yip, L. S. C., \& Luk, S. T. K. (2011). An examination of the differences in retail service evaluation between domestic and tourist shoppers in Hong Kong. Tourism Management, 32(3), 520-533. https://doi.org/10.1016/j.tourman.2010.0 4.004

Michon, R., \& Chebat, J. C. (2004). Crosscultural mall shopping values and habitats - A comparison between English- and French-speaking Canadians. Journal of Business Research, 57(8), 883-892. https://doi.org/10.1016/S01482963(02)00291-6

Nguyen, T. T. m., Nguyen, T. D., \& Barrett, N. J. (2007). Hedonic shopping motivations, supermarket attributes, and shopper loyalty in transitional markets: Evidence from Vietnam. Asia Pacific Journal of Marketing and Logistics, 19(3), 227-239. https://doi.org/10.1108/13555850710772 914

Oh, J. Y. J., Cheng, C. K., Lehto, X. Y., \& O'Leary, J. T. (2004). Predictors of tourists' shopping behaviour: Examination of socio-demographic characteristics and trip typologies. Journal of Vacation Marketing, 10(4), 308-319.

https://doi.org/10.1177/13567667040100 0403

Park, K. S., Reisinger, Y., \& Kang, H. J. (2008). Visitors' motivation for attending the South Beach Wine and Food Festival, Miami beach, Florida. Journal of Travel and Tourism Marketing, 25(2), 161-181. https://doi.org/10.1080/10548400802402 883

Richbell, S. \&, \& Kite, V. (2007). Night shoppers in the "open 24 hours" supermarket: a profile. International Journal of Retail \& Distribution Management, 18(4), 36-44. https://doi.org/10.1108/MBE-09-2016- 
0047

Stephen P. Robbins. (2001). Organizational Behavior. International, Prentice Hall. Retrieved from http://wwwuser.gwdg.de/ uwuf/pdfdatei /orga/Chapt1.pdf

Sugiyono, 2014. Metode Penelitian Kuantitatif, Kualitatif, dan R \& D. Bandung: Alfabeta.

Suhartanto, D., Ruhadi, \& Triyuni, N. N. (2016). Tourist loyalty toward shopping destination: The role of shopping satisfaction and destination image. European Journal of Tourism Research, 13(January), 84-102.

Thaichon, P., Lobo, A., \& Quach, T. N. (2016). The Moderating Role of Age in Customer Loyalty Formation Process. Services Marketing Quarterly, 37(1), 52-70.

https://doi.org/10.1080/15332969.2015.1 112184

Timothy, D. J., \& Butler, R. W. (1995). Cross-border shopping - a NorthAmerican perspective. Annals of Tourism Research, 22(1), 16-34. https://doi.org/10.1016/01607383(94)00052-t

Tosun, C., Temizkan, S. P., Timothy, D. J., \& Fyall, A. (2007). Tourist shopping experiences and satisfaction. International Journal of Tourism Research, $\quad 9(2), \quad 87-102$. https://doi.org/10.1002/jtr.595

Turner, L. W., \& Reisinger, Y. (2000). Shopping satisfaction for domestic tourists. Journal of Retailing and Consumer Services, 8(1), 15-27. https://doi.org/10.1016/S09696989(00)00005-9

Wong, I. K. A., \& Wan, Y. K. P. (2013). A Systematic Approach to Scale Development in Tourist Shopping Satisfaction: Linking Destination Attributes and Shopping Experience.
Journal of Travel Research, 52(1), 2941.

https://doi.org/10.1177/00472875124572 63

Yeung, S., Wong, J., \& Ko, E. (2004). Preferred shopping destination: Hong Kong versus Singapore. International Journal of Tourism Research, 6(2), 8596. https://doi.org/10.1002/jtr.474

Yüksel, A., \& Yüksel, F. (2007). Shopping risk perceptions: Effects on tourists' emotions, satisfaction and expressed loyalty intentions. Tourism Management, 28(3), 703-713. https://doi.org/10.1016/j.tourman.2006.0 4.025 